\title{
Modulation of Fibronectin Synthesis and Fibronectin Binding During Transformation and Differentiation of Mouse AKR Fibroblasts
}

\author{
IAMES VARANI* AND SUBHAS CHAKRABARTY \\ Department of Pathology, University of Michigan Medical School, Ann Arbor, Michigan \\ 48109 (J.V.); Department of Pharmacology, Baylor College of Medicine,
}

Houston, Texas 77030 (S.C.)

\begin{abstract}
In previous studies it was shown that transformation of AKR fibroblasts with 3-methylcholanthrene was associated with a loss of surface fibronectin and that induction of differentiation of the transformed cells with N,N-dimethylformamide (DMF) was associated with reacquisition of surface fibronectin (Chakrabarty et al., J. Cell. Physiol. 133:415, 1987). It is shown in the present study that changes in surface fibronectin reflect altered fibronectin synthesis and altered fibronectin binding. Both the nontransformed cells (AKR-2B) and their transformed counterparts (AKR-MCA) bound ${ }^{125}$-fibronectin in a receptor-like fashion, but the AKRMCA cells had only $20 \%$ of the receptors found on the AKR-2B cells. Whole cell extracts prepared from the AKR-2B cells and separated by sodium dodecyl sufatepolyacrylamide gel electrophoresis under reducing conditions were examined for ${ }_{125}$ I-fibronectin binding. Under these conditions, the majority of binding occurred to moieties with molecular weights of $180 \mathrm{kD}, 150 \mathrm{kD}$, and $97 \mathrm{kD}$. Binding to similar moieties on the AKR-MCA cells was virtually absent but occurred rapidly after treatment with DMF. The appearance of these moieties paralleled the acquisition of ${ }^{125} \mathrm{I}$-fibronectin binding activity by whole cells. Antibodies to the fibronectin receptor isolated from human placenta reacted with the DMF-sensitive moieties in immunoblot assays. Both the appearance of the fibronectin binding moieties and the acquisition of ${ }^{125}$-fibronectin binding activity by whole cells occurred within $6 \mathrm{hr}$ of DMF treatment and increased over the subsequent 4 day period. The time course of these events paralleled closely the time course for induction of fibronectin biosynthesis by DMF. These changes in fibronectin binding and fibronectin production were associated with alterations in cell-substrate adhesion. The AKR-2B cells rapidly attached and spread on bovine serum albumin-coated dishes and on fibronectin-coated dishes, whereas the AKR-MCA cells were less adhesive on both substrates. Capacity to attach and spread was regained concomitantly with the induction of fibronectin binding and fibronectin production. Adhesion on both substrates was partially inhibited by antibodies to the fibronectin receptor and by RGDS. These studies suggest that fibronectin production and fibronectin binding are coregulated in AKR fibroblasts and that they function together to bring about changes in cell-substrate adhesion.
\end{abstract}

Transformation of rodent cells with a variety of agents (physical, chemical, or viral) results in a dramatic decrease in surface fibronectin (Hynes, 1976; Vaheri and Mosher, 1978; Hayman et al., 1981; Alitalo et al., 1982; Chakrabarty et al., 1987). It has recently been shown that transformation of rat fibroblasts with a single oncogene (Ha-Ras) has a similar effect (Chakrabarty et al., 1989b). Loss of surface fibronectin is not unique to rodent cells. In cells of many other species, including humans, malignant variants often have less fibronectin on their surface than their nonmalignant counterparts (Vaheri and Ruoslahti, 1975; Yamada et al., 1978; Smith et al., 1981; TaylorPapadimitriou et al., 1981; Varani et al., 1989).
Whereas loss of surface fibronectin is a consistent feature of transformation, agents that induce the expression of normal phenotypic characteristics in transformed cells (i.e., differentiation agents) cause the reacquisition of surface fibronectin (Hayman et al., 1980; Milhaud et al., 1980; Carlin et al., 1982; Sporn and Roberts, 1983; Tanaka and Nishida, 1985; Marks et al., 1985; Chakrabarty et al., 1987, 1988, 1989a; Varani et al., 1989).

Received June 30, 1989; accepted January 30, 1990.

*To whom reprint requests/correspondence should be addressed. 
What accounts for the alterations in surface fibronectin expression during transformation and differentiation is not fully understood. Alterations either in the production of fibronectin or in fibronectin binding could be responsible. Recent studies with human fibroblasts (Ignotz and Massague, 1987; Roberts et al., 1988) and with murine 3T3 cells (Ryseck et al., 1989) suggest that fibronectin production and fibronectin receptor expression may be coregulated. In the present study we have examined the relationship between fibronectin production and fibronectin binding in murine AKR-2B fibroblasts and their transformed counterparts, AKRMCA cells. We show here that both fibronectin synthesis and fibronectin binding are reduced in the AKRMCA cells relative to the AKR-2B cells. It is further shown that treatment of the AKR-MCA cells with N,Ndimethylformamide (DMF), an agent previously shown to induce differentiation of AKR-MCA cells (Chakrabarty et al., 1984, 1985; Levine et al., 1985) and to induce the reexpression of surface fibronectin on these cells (Chakrabarty et al., 1987), leads to a rapid and concomitant induction of fibronectin synthesis and fibronectin binding. Alterations in fibronectin synthesis and fibronectin binding are directly correlated with alterations in cell-substrate adhesion. Taken together, these data suggest that alterations in adhesive properties that accompany transformation and differentiation of AKR mouse fibroblasts are the result of modulation of surface fibronectin, which in turn results from coordinated alterations in fibronectin synthesis and fibronectin receptor expression.

\section{MATERIALS AND METHODS}

\section{Cells}

AKR mouse fibroblasts (AKR-2B) and their 3-methylcholanthrene-transformed counterparts (AKR-MCA) were used in this study. Both cell lines were maintained in monolayer culture using McCoy's 5 A medium supplemented with $10 \%$ fetal bovine serum as culture medium. Growth was at $37^{\circ} \mathrm{C}$ and $5 \% \mathrm{CO}_{2}$. The cells were subcultured by trypsinization as required. The AKR-MCA cells were induced to differentiate by treatment with $1 \%(\mathrm{v} / \mathrm{v}) \mathrm{DMF}$ in culture medium. The effects of DMF on the biological properties of the AKR$2 B$ and AKR-MCA cells have been described in previous reports (Chakrabarty et al., 1984, 1985, 1987; Levine et al., 1985).

\section{Reagents}

Human plasma fibronectin was obtained from GIBCO (Grand Island, NY), and rabbit polyclonal antifibronectin was obtained from Dako (Santa Barbara, CA). Rabbit polyclonal antibodies to the human fibronectin receptor were obtained from Telios (San Diego, CA). The synthetic peptide from the cell-binding domain of fibronectin (RGDS) and an inactive control peptide (GRADSP) were obtained from Telios. Analysis of the fibronectin by sodium dodecyl sulfate-polyacrylamide gel electrophoresis (SDS-PAGE) under reducing conditions revealed a single band at $M_{r} 220-240 \mathrm{kD}$. It reacted with antifibronectin in enzyme-linked immunosorbent assay (ELISA) at antibody dilutions between $1: 1$ and $1: 10^{5}$ but did not react with rabbit polyclonal antibodies to laminin, thrombospondin, or type IV col- lagen. Each of these antibody preparations reacted with the appropriate antigen in ELISA. The antifibronectin, likewise, did not react with laminin, thrombospondin, or type IV collagen at any dilution between $1: 1$ and $1: 10^{6}$. The fibronectin stimulated attachment and spreading of a fibronectin-sensitive murine fibrosarcoma cell line at concentrations as low as $0.5 \mu \mathrm{g} / 35$ $\mathrm{mm}$ (diameter) dish.

\section{Biosynthetic labeling}

Cells were plated in $100 \mathrm{~mm}$ (diameter) culture dishes at an approximate density of $5 \times 10^{6}$ cells per dish. The cells were allowed to attach and spread for 1 $\mathrm{hr}$. They were then treated with $1 \% \mathrm{DMF}(\mathrm{v} / \mathrm{v})$. At various times after DMF treatment, the cells were incubated for $1 \mathrm{hr}$ in culture medium containing $100 \mu \mathrm{Ci}$ / dish of ${ }^{35} \mathrm{~S}$-methionine $(1,000-1,400 \mu \mathrm{Ci} / \mu$ mole; NEN, Boston, MA). After the $1 \mathrm{hr}$ incubation, the cells were lysed in a solution of phosphate-buffered saline (PBS) containing three detergents ( $1 \%$ Triton X-100, $0.5 \%$ sodium deoxycholate, and $0.1 \%$ SDS; all obtained from Sigma Chemical Co., St. Louis, MO) and protease inhibitors, including $20 \mathrm{mM}$ EDTA, $5 \mathrm{mM}$ N-ethyl maleimide, $2 \mathrm{mM}$ phenylmethylsulfonyl fluoride (PMSF), and $10 \mu \mathrm{l} / 10 \mathrm{ml}$ of a protease inhibitor cocktail containing: leupeptin, $1 \mathrm{mg} / \mathrm{ml}$; antipain, $2 \mathrm{mg} / \mathrm{ml}$; benzamidine, $10 \mathrm{mg} / \mathrm{ml}$; aprotinin, 10,000 kallikrein-inactivating units $/ \mathrm{ml}$; chymostatin, $1 \mathrm{mg} / \mathrm{ml}$; and pepstatin, $1 \mathrm{mg} / \mathrm{ml}$, as described by Ronnett et al. (1984) in studies on the insulin receptor. All the protease inhibitors were obtained from Sigma Chemical Co. The cell lysates were frozen at $-80^{\circ} \mathrm{C}$, thawed, and clarified by ultracentrifugation $(37,000 \mathrm{~g}$ for $60 \mathrm{~min}$ ). Immunoreactive fibronectin was precipitated with a 1:100 dilution of the rabbit antifibronectin and protein A-Sepharose (Sigma Chemical Co.) according to the protocol of Ruddon et al. (1979). Normal rabbit serum served as a control. The washed immunoprecipitates were eluted with boiling (5 $\mathrm{min})$ in twofold concentrated Laemmli (1970) SDS-PAGE sample buffer containing 2\% 2-merceptoethanol. The immunoprecipitated material was fractionated on a $5 \%$ polyacrylamide gel employing the Laemmli system. Radioactive bands were visualized by fluorography with $\mathrm{En}^{3} \mathrm{Hance}$ (NEN), exposing the dried gels to X-ray film (Kodak XAR-2) for 2 days. In addition, a small sample of each immunoprecipitate was counted in a $\beta$-scintillation counter to quantitate ${ }^{35} \mathrm{~S}-\mathrm{methionine}$ incorporation. The amount of radioactivity precipitated with antifibronectin was compared with the amount precipitated with $10 \%$ (final) trichloroacetic acid (TCA) to determine the percentage of total synthesized protein accounted for by fibronectin.

\section{Immunoblotting}

Whole cell extracts (nonradioactive) were fractionated by SDS-PAGE as described above and immunoblotted with antifibronectin as previously described (Chakrabarty et al., 1987). Briefly, the proteins fractionated by SDS-PAGE were electrophoretically transferred onto nitrocellulose sheets. The binding profiles of antibodies were assessed as follows. Following transfer, the nitrocellulose sheets were incubated in a blocking solution containing 3\% bovine serum albumin, $0.05 \%$ Tween 20 in PBS, pH 7.2 , at $4^{\circ} \mathrm{C}$ overnight. The sheets were then washed once with $1 \%$ bovine serum 
albumin Tween 20 in PBS and incubated with antibodies (1:1,000 dilution) in the same buffer on a gently rocking platform for $3-4 \mathrm{hr}$ at room temperature. The sheets were washed four times with $1 \%$ bovine serum albumin Tween 20 and incubated with the same buffer containing 500,000 cpm ${ }^{125}$ I-protein A (ICN, Irvine, CA) overnight on a gently rocking platform at room temperature. Following incubation, the sheets were washed several times in PBS containing $0.05 \%$ Tween 20 and air dried. The binding of antibodies and ${ }^{125} \mathrm{I}-$ protein $\mathrm{A}$ to the antigens on the nitrocellulose sheets was visualized by autoradiography. As controls, other nitrocellulose sheets containing the transferred proteins were similarly treated with normal rabbit serum (1:1,000 dilution) or with ${ }^{125}$ I-protein $\mathrm{A}$ in the absence of antibodies. No ${ }^{125}$ I-protein A binding was observed in the controls. Whole cell extracts were examined for binding of antibodies to the fibronectin receptor in the same manner.

\section{ELISAs}

ELISAs were used to quantitate the amount of immunoreactive fibronectin secreted into the culture medium. For this, cells were plated at $3 \times 10^{5}$ cells/dish in $35 \mathrm{~mm}$ (diameter) cell culture dishes. Cells were allowed to attach and spread for $1 \mathrm{hr}$. Following this, the cells were washed two times in serum-free culture medium and incubated with serum-free McCoy's 5A medium supplemented with $200 \mu \mathrm{g} / \mathrm{ml}$ of bovine serum albumin. DMF $(1 \% \mathrm{v} / \mathrm{v})$ was added to one-half the wells. At various times later, $200 \mu \mathrm{l}$ of each culture fluid was added to wells of a 96-well plate (Falcon Plastics, Oxnard, CA) from lots that had been prescreened for acceptability in ELISA reactions and incubated for $4 \mathrm{hr}$ at $37^{\circ} \mathrm{C}$. Culture medium alone served as a control. Purified human plasma fibronectin $(0.5-0.0005 \mu \mathrm{g} /$ well) was also added to the assay plate in the same culture medium to serve as a standard. After the $4 \mathrm{hr}$ incubation, the fluids were removed from the wells, and the assays were run exactly as described previously (Varani et al., 1983).

\section{${ }^{125}$ I-fibronectin binding assay}

Fibronectin was iodinated with $\mathrm{Na}^{125} \mathrm{I}$ (Amersham, Arlington Heights, IL) using the chloramine T method to a specific activity of approximately $1 \mu \mathrm{Ci} / \mu \mathrm{g}$. Unreacted $\mathrm{Na}^{125} \mathrm{I}$ was removed from the protein by gel filtration chromatography on Biogel P-10 (LKB, Uppsala, Sweden). Binding assays were performed as previously described, with some modifications (Riser et al., 1988; Chakrabarty et al., 1989b). Cells $\left(3 \times 10^{5}\right)$ were seeded into 24-well culture dishes in McCoy's 5A medium containing $10 \%$ fetal bovine serum and incubated overnight at $37^{\circ} \mathrm{C}$ and $5 \% \mathrm{CO}_{2}$ in a humidified incubator. The cells in monolayer were then washed twice with binding medium (serum-free McCoy's 5A medium containing $20 \mathrm{mM}$ Hepes, $\mathrm{pH} 7.4$, and $500 \mu \mathrm{g}$ of bovine serum albumin $/ \mathrm{ml}$ ) and incubated for an additional 2 $\mathrm{hr}$ at $37^{\circ} \mathrm{C}$ and $5 \% \mathrm{CO}_{2}$ in binding medium. Following this, the binding medium was removed and appropriate amounts of ${ }^{125}$ I-labeled fibronectin in fresh binding medium in the presence or absence of 100 -fold excess of unlabeled fibronectin was added. The cells were incubated at $37^{\circ} \mathrm{C}$ and $5 \% \mathrm{CO}_{2}$ for $1 \mathrm{hr}$ and then washed four times in binding medium, with gentle shaking on a horizontal shaker. Following the last wash, the cells were detached from the culture dishes by trypsinization at $37^{\circ} \mathrm{C}$, and the entire contents were transferred to test tubes for counting. The culture wells were rinsed once with the trypsin solution, which was then combined with corresponding test tubes for counting. All assays were performed in triplicate, with parallel cultures used to determine cell number. The amount of radioactivity specifically bound was determined by the following formula.

cpm specifically bound

$=$ total cpm bound in the absence of unlabeled ligand

cpm bound in the presence of 100 -fold excess of unlabeled ligand

Nonspecific fibronectin binding was found to be in the range of $20-25 \%$ of the total binding and was subtracted from total binding in each experiment.

\section{${ }^{125}$ I-fibronectin binding to cell lysates}

Cells were grown in $100 \mathrm{~mm}$ (diameter) dishes to an approximate density of $7.5 \times 10^{6}$ cells/dish. Cells extracts were prepared as described previously (Chakrabarty et al., 1987) and separated by SDS-PAGE under reducing conditions. The proteins were electrophoretically transferred onto nitrocellulose sheets. The binding profile of ${ }^{125} \mathrm{I}$-fibronectin was assessed as follows. Following transfer, the nitrocellulose sheets were incubated in a blocking solution containing $3 \%$ bovine serum albumin, $0.05 \%$ Tween 20 in PBS, pH 7.2, at $4^{\circ} \mathrm{C}$ overnight. The sheets were then washed once with $1 \%$ bovine serum albumin Tween 20 in PBS and incubated with ${ }^{125}$ I-fibronectin $(8 \mathrm{nM})$ with and without a 100 fold excess of unlabeled fibronectin in the same buffer on a gently rocking platform for $3-4 \mathrm{hr}$ at room temperature. The sheets were washed four times with $1 \%$ bovine serum albumin Tween 20. Following incubation, the sheets were washed several times in PBS containing $0.05 \%$ Tween 20 and air dired. The binding of ${ }_{125}$ I-fibronectin was visualized by autoradiography using Kodak XAR-2 film. This procedure has been used previously by others to identify fibronectin-binding and laminin-binding moieties (Codogno et al., 1987; Kleinman et al., 1988).

\section{Adhesion assay}

Cells were examined for attachment and spreading on plastic culture dishes in the presence of bovine serum albumin. The cells were harvested from culture, washed twice in serum-free medium, and added to the wells of a 24-well cluster dish ( $3 \times 10^{5}$ cells per well) in serum-free medium supplemented with $200 \mu \mathrm{g} / \mathrm{ml}$ of bovine serum albumin. The wells were incubated at $37^{\circ} \mathrm{C}$, and, at various times later, the nonattached cells were removed and counted. The wells were then flooded with $2 \%$ glutaraldehyde, and the percentage of spread cells was assessed microscopically. By combining the two values, a percentage of the originally added cells that were attached and spread at each time point was obtained. In some experiments, wells were treated for $2 \mathrm{hr}$ with human plasma fibronectin prior to use. The adhesion assay was then carried out in the same manner. 

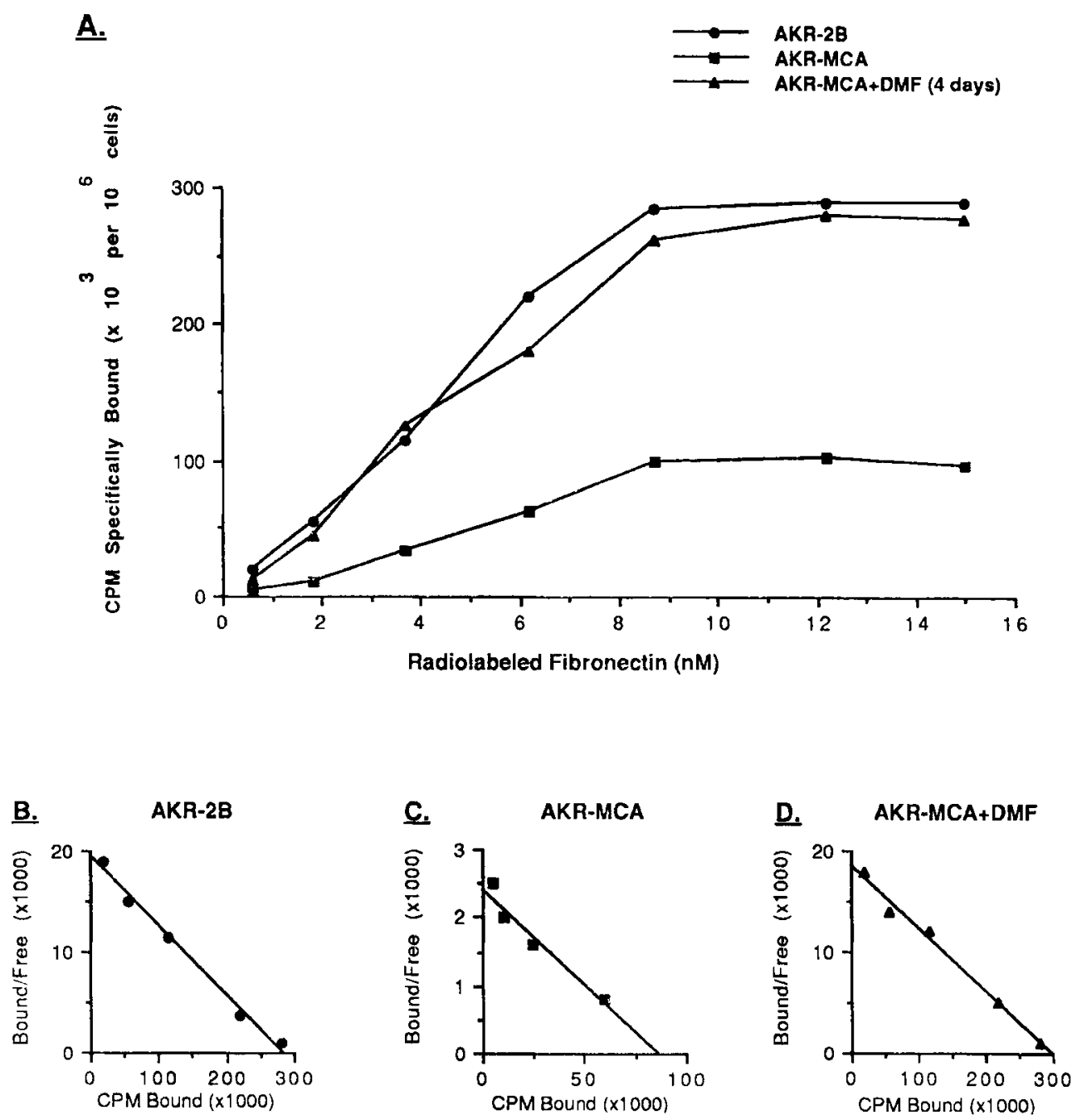

Fig. 1. A: Binding studies with ${ }^{125} \mathrm{I}-$ fibronectin. Binding assays were carried out as described in Materials and Methods. Values shown represent the averages based on triplicate samples/data point in a single experiment in which standard deviations were within $10 \%$ of the averages. Nonspecific binding, which routinely accounted for $20-$

$25 \%$ of the total binding, was determined in the presence of 100 -fold excess unlabeled fibronectin and has been subtracted from each data point. The experiment was repeated three times with similar results. B-D: Scatchard analysis of the binding data.

\section{RESULTS}

\section{Fibronectin-binding by AKR-2B and AKR-MCA-cells}

Our previous studies showed that the AKR-2B cells were much more adhesive to fibronectin than the AKRMCA cells and that DMF induced adhesion to fibronectin in the AKR-MCA cells (Chakrabarty et al., 1987). It was of interest, therefore, to determine if differences in response to fibronectin were related to differential fibronectin binding capacity. To determine this, we used a ${ }^{125}$ I-fibronectin-binding assay to compare AKR-2B and AKR-MCA cells. With both cell lines, binding of ${ }^{125}$ I-fibronectin occurred in a receptor-like fashion. That is, binding was concentration-dependent, saturable, and inhibitable with excess unlabeled fibronectin. Binding curves for both cell lines are shown in Figure 1. It can be seen that the number of binding sites/cell distinguished the two cell lines. We estimated that there were $8.0 \times 10^{4}$ binding sites/AKR-2B cell and $2.0 \times 10^{4}$ sites/AKR-MCA cell. In addition, the average affinity of binding was slightly greater to the AKR-2B than AKR-MCA cells (Kd 22 vs. $45 \mathrm{nM}$ ) (Fig. 1). Effects of DMF on ${ }^{125}$ I-fibronectin binding by the AKR-MCA cells was examined next. As can be seen in Figure 1, treatment of the AKR-MCA cells with 1\% DMF for 4 days stimulated fibronectin binding in these cells to a level comparable to that observed with the AKR-2B cells. The same treatment had only minimal effect on fibronectin binding by the AKR-2B cells (not shown).

To examine the time course of DMF-mediated changes in fibronectin binding, AKR-MCA cells were plated in wells of a 24-well dish and incubated for varying periods of time with $1 \% \mathrm{DMF} .{ }^{125}$ I-fibronectin binding studies were then carried out in the normal manner using a single concentration of fibronectin (8 nM). DMF treatment induced a detectable increase in fibronectin binding by the AKR-MCA cells as early as $6 \mathrm{hr}$ 
TABLE 1. ${ }^{125}$ I-fibronectin binding to AKR-2B and AKR-MCA fibroblasts ${ }^{1}$

\begin{tabular}{llrc}
\hline Cells & $\begin{array}{c}\text { DMF } \\
\text { treatment }\end{array}$ & $\begin{array}{c}\text { cPM specifically } \\
\text { bound per } \\
10^{6} \text { cells }\end{array}$ & $\begin{array}{c}\text { Percent of } \\
\text { AKR-2B } \\
\text { control }\end{array}$ \\
\hline AKR-2B & None & 120,000 & \\
AKR-MCA & None & 45,000 & 37.5 \\
AKR-MCA & 2 Hours & 50,000 & 41.6 \\
& 6 Hours & 58,000 & 48.4 \\
& 24 Hours & 64,000 & 53.3 \\
& 48 Hours & 70,000 & 58.3 \\
& 72 Hours & 82,000 & 68.3 \\
& 96 Hours & 110,000 & 91.6 \\
\hline
\end{tabular}

${ }^{1}$ Binding assays were performed in 24 well tissue culture plates according to procedures described in Materials and Methods. The values represent the average of three binding experiments (with a standard error of less than $5 \%$ ) using age of three binding experiments (with a standard error of less than $5 \%$ ) using one saturating dose of ${ }^{2}$ I-fibronectin $(8 \mathrm{nM})$ for each well. Nonspecif
has been subtracted from the total amount of radioactivity bound.

after treatment. The increase continued over the following 3 days (Table 1 ).

We next examined binding of ${ }^{125}$ I-fibronectin to whole cell extracts prepared from AKR-2B and AKRMCA cells by detergent lysis. Control cells and cells treated with $1 \% \mathrm{DMF}$ for varying periods of time were lysed and separated by electrophoresis on a 7.5\% SDSpolyacrylamide gel under reducing conditions. The separated proteins were then transferred to nitrocellulose as described in Materials and Methods and probed with ${ }^{125}$ I-fibronectin. Figure 2 shows the pattern typically seen after autoradiography. Distinct binding moieties at $\mathrm{M}_{\mathrm{r}} 180 \mathrm{kD}, 150 \mathrm{kD}$, and $97 \mathrm{kD}$ were visible in the extracts prepared from the AKR-2B cells (lane 6). Binding was specific in that 100 -fold excess of unlabeled fibronectin completely inhibited binding (lane 7). In contrast to the results obtained with AKR-2B cells, there was almost no binding to extract proteins from the untreated AKR-MCA cells (lane 1). Binding was seen in these cells, however, after treatment with DMF. Bands could be seen as early as $6 \mathrm{hr}$ after treatment (not shown) and were clearly distinct by 1 day after treatment (lane 2). The bands increased in density over the following 3 days (lanes 3-5) so that by day 4 they were essentially as dark as the bands from the AKR-2B cells. A small but significant amount of binding was also observed to moieties in the range of 50-60 $\mathrm{kD}$.

The relationship between these fibronectin-binding moieties and the well-characterized integrin receptor for fibronectin is not known. To address this issue, we examined binding of rabbit polyclonal antibodies prepared against the human fibronectin receptor from placenta by whole cell extracts of the AKR-2B and AKRMCA cells. Antibody binding and detection was done as described in Materials and Methods. As is shown in Figure 3, antibodies to the fibronectin receptor exhibited a broad band of reactivity in the $150-180 \mathrm{kD}$ range with extract from the AKR-2B cells (lane 3). Antibody binding to this region of the gel was absent with extract from control AKR-MCA cells (lane 1) but was seen in extract prepared from AKR-MCA cells one day after treatment with $1 \%$ DMF (lane 2). In addition to binding in this region of the gel, the antifibronectin antibody reacted with moieties in the $97 \mathrm{kD}$ region of the gel and with lower molecular weight bands. Binding to these moieties, however, did not distinguish extracts from three populations.

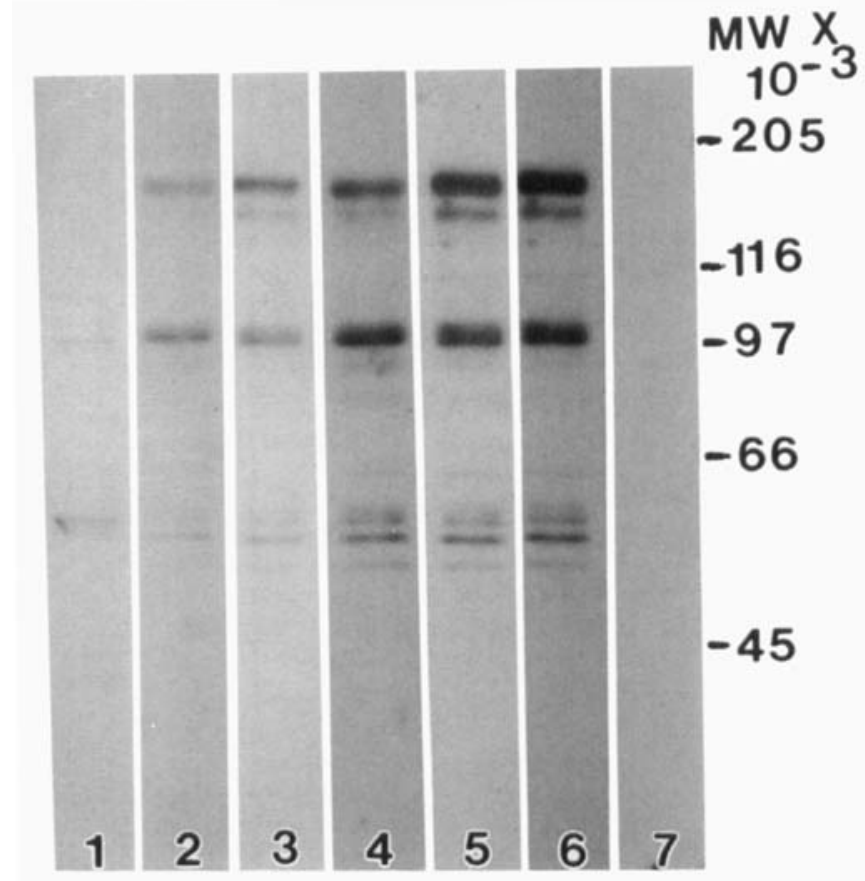

Fig. 2. ${ }^{125}$ I-fibronectin binding to cell lysate proteins obtained from AKR-2B and AKR-MCA cells. Cell lysate proteins were prepared and binding studies carried out as described in Materials and Methods. Forty micrograms of cell lysate protein were used per lane, and each lanes was probed with ${ }^{125}$ I-fibronectin at a concentration of $8 \mathrm{nM}$. Lane 1: AKR-MCA; lanes 2-5: AKR-MCA treated with 1\% DMF for $1,2,3$, and 4 days respectively; lane 6: AKR-2B; lane 7: AKR-2B in the presence of 100 -fold excess nonlabeled fibronectin.

\section{Effects of DMF on fibronectin production by AKR-MCA cells}

In our previous studies (Chakrabarty et al., 1987) we showed that fibronectin production was lower in AKRMCA cells than in AKR-2B cells and that it was stimulated in AKR-MCA cells by treatment with DMF for 4 days. We have in the present study examined the time course of fibronectin production in DMF-treated AKR-MCA cells. Biosynthetic labeling/immunoprecipitation was used in the first series of experiments. Table 2 shows the time course of DMF-induced changes in total incorporation of ${ }^{35} \mathrm{~S}$-methionine into $10 \%$ TCAprecipitable material (a measure of protein synthesis). Cells treated for 2 or $4 \mathrm{hr}$ with DMF were not significantly different from control cells. Reduced incorporation was observed by $5 \mathrm{hr}$ (approximately $20 \%$ reduction vs. untreated AKR-MCA cells examined in the same manner) and continued through $24 \mathrm{hr}$. After 24 $\mathrm{hr}$, total incorporation of ${ }^{35} \mathrm{~S}$-methionine into TCA-precipitable material from cultures of DMF-treated cells was only $28 \%$ of the amount incorporated into TCAprecipitable material from control cultures. On a per cell basis, total incorporation into TCA-precipitable material was reduced by approximately $50 \%$ in the treated cells compared with control cells.

Table 2 also shows the effect of DMF treatment on incorporation of ${ }^{35} \mathrm{~S}$-methionine into antifibronectinprecipitable material. Increased fibronectin biosynthesis (as a function of total protein synthesis) was de- 


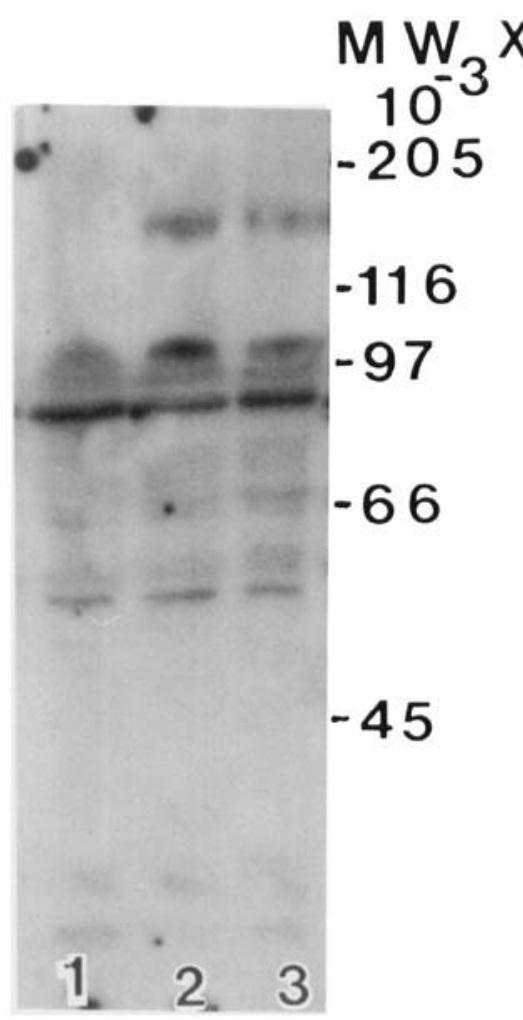

Fig. 3. Immunoblotting of cell lysate proteins obtained from AKR2B and AKR-MCA cells. Cell lysate proteins were separated by SDSPAGE, transferred to nitrocellulose, and blotted with antifibronectin receptor and ${ }^{125} \mathrm{I}$-protein $\mathrm{A}$ as described in Materials and Methods. Lane 1: AKR-MCA; lane 2: AKR-MCA treated for 1 day with $1 \%$ DMF; lane 3: AKR-2B.

TABLE 2. Time course of DMF stimulation of total protein synthesis and fibronectin synthesis in AKR-MCA cells

\begin{tabular}{lcc}
\hline Group & $\begin{array}{c}\text { 35S-methionine } \\
(\text { cpm incorporated })^{2} \\
\left(\times 10^{6}\right)\end{array}$ & $\begin{array}{c}\text { Fibronectin } \\
(\% \text { of total } \\
\text { protein })^{3}\end{array}$ \\
\hline No treatment & 2.35 & 0.03 \\
DMF 2 hours & 2.40 & 0.01 \\
DMF 4 hours & 2.35 & 0.04 \\
DMF 5 hours & 2.03 & 0.03 \\
DMF 6 hours & 2.01 & 0.14 \\
DMF 8 hours & 1.67 & 0.18 \\
DMF 24 hours & 0.53 & 0.25 \\
\hline
\end{tabular}

${ }^{1}$ AKR-MCA cells $\left(1 \times 10^{7}\right)$ were plated in $100 \mathrm{~mm}$ (diameter) dishes using McCoy's 5A medium supplemented with $10 \%$ fetal bovine serum as culture medium. At various times later, the cultures were treated with $1 \%$ DMF (final dium. At various times later, the cultures were treated with $1 \%$ DMF (final
concentration). At the end of the incubation period, the cells were incubated for $1 \mathrm{hr}$ with $100 \mu \mathrm{Ci}$ of ${ }^{35} \mathrm{~S}$-methionine. Cell lysates were prepared and analyzed for total incorporation of ${ }^{35} \mathrm{~S}$-methionine into TCA-precipitable material and into antifibronectin-precipitable material.

${ }^{2}$ Values represent average cpm incorporated into $100 \mu l$ of cell extract based on duplicate samples/data point in a single experiment in which the individual values were within $17 \%$ of the mean values. The experiment was repeated two values were within $17 \%$ of
times, with similar results.

times, with similar results.
${ }^{3}$ Values represent the percentage of the cpm incorporated into total protein that were incorporated into antifibronectin-precipitable material.

tected by $6 \mathrm{hr}$. The percentage increase in fibronectin production was much greater than the percentage decrease in total protein synthesis at 6,8 , and $24 \mathrm{hr}$, indicating that the increase reflected actual increases in fibronectin synthesis as well as decreased synthesis

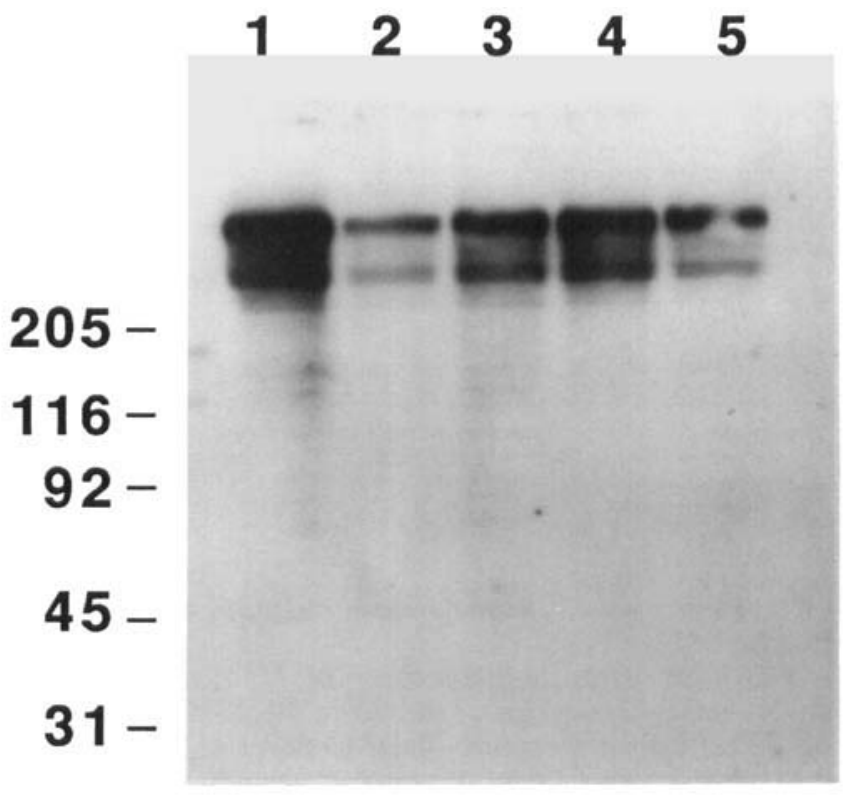

Fig. 4. Immunoblotting of cell lysate proteins obtained from AKR2B and AKR-MCA cells. Cell lysate proteins were separated by SDSPAGE, transferred to nitrocellulose, and blotted with antifibronectin and ${ }^{125}$ I-protein $\mathrm{A}$ as described in Materials and Methods. Lane 1: AKR-2B; lane 2: AKR-MCA; lanes 3-5: AKR-MCA treated with $1 \%$ DMF for 2 days, 1 day or $6 \mathrm{hr}$, respectively.

of nonfibronectin proteins. Examination of antifibronectin-precipitated material from the DMF-treated AKR-MCA cells by SDS- PAGE under reducing conditions and autoradiography revealed a closely spaced doublet with molecular weights of $220-240 \mathrm{kD}$. Identical forms were seen in extracts of the AKR-2B and AKR-MCA cells (not shown). Thus there appeared to be no qualitative changes in the molecular forms of fibronectin produced in response to DMF.

Immunoblotting was used as a second means of visualizing changes in fibronectin production. Whole cell extracts were separated by SDS-PAGE and immunoblotted as described in Materials and Methods. Figure 4 shows antifibronectin reactive moieties in whole cell extracts prepared from AKR-2B cells and AKR-MCA cells with and without DMF. Extracts prepared from the AKR-MCA cells (lane 2) contained significantly less antifibronectin reactive material than extracts from AKR-2B cells (lane 1). However, extracts obtained from AKR-MCA cells $6 \mathrm{hr}$ after treatment with DMF (lane 5) showed increased amounts of fibronectin. By days 1 and 2 (lanes 3 and 4), there was no detectable difference between AKR-2B cells and DMF-treated AKR-MCA cells.

ELISAs were used as a third means of identifying changes in fibronectin production following DMF treatment. Culture fluids obtained from cells $30 \mathrm{~min}$ or $2 \mathrm{hr}$ after DMF treatment showed slightly increased amounts of fibronectin. Culture fluids obtained $6 \mathrm{hr}$ or more after treatment showed significantly increased amounts (Table 3).

\section{Effects of DMF on AKR-MCA cell adhesion}

We knew from our previous studies that the AKR-2B cells rapidly attached and spread on bovine serum al- 
TABLE 3. Time course of DMF stimulation of fibronectin production in AKR-MCA cells ${ }^{1}$

\begin{tabular}{lc}
\hline Group & $\begin{array}{c}\text { Nanograms of fibronectin } \\
1 \times 10^{5} \text { cells }\end{array}$ \\
\hline $30 \mathrm{Min}$ control & $60 \pm 10$ \\
$30 \mathrm{Min}$ DMF & $75 \pm 5$ \\
$2 \mathrm{Hr}$ control & $68 \pm 4$ \\
$2 \mathrm{Hr}$ DMF & $78 \pm 10$ \\
$4 \mathrm{Hr}$ control & $96 \pm 30$ \\
$4 \mathrm{Hr}$ DMF & $150 \pm 11$ \\
$6 \mathrm{Hr}$ control & $70 \pm 4$ \\
$6 \mathrm{Hr}$ DMF & $140 \pm 8$ \\
$18 \mathrm{Hr}$ control & $150 \pm 8$ \\
$18 \mathrm{Hr}$ DMF & $510 \pm 20$ \\
\hline
\end{tabular}

${ }^{1}$ Culture fluids were obtained from control and DMF-treated cells and analyzed for fibronectin production by ELISA. Values represent average nanograms of fibronectin $/ 1 \times 10^{5}$ cells \pm differences between individual values and averages based on duplicate samples/data point in a single experiment. The experiment was repeated three times with similar results.

bumin-coated dishes, whereas the AKR-MCA cells attached and spread much more slowly (Chakrabarty et al., 1987). That the rapid adhesion response of the AKR-2B cells was due to surface fibronectin was strongly suggested by the finding that antibody to fibronectin but not to laminin inhibited this response. We therefore sought to determine in the present study if changes in AKR-MCA cell adhesion would parallel changes in fibronectin/fibronectin receptor expression following DMF treatment. Cells were grown in monolayer culture and treated with 1\% DMF for varying periods of time. At the end of the treatment period, the cells were harvested by trypsinization and assayed for attachment and spreading on bovine serum albumincoated dishes as described in Materials and Methods. AKR-MCA cells pretreated with DMF for $3 \mathrm{hr}$ (but not for 1 or $2 \mathrm{hr}$ ) showed increased adhesion over untreated AKR-MCA cells. Increased attachment and spreading was detected by $2 \mathrm{hr}$ (total elapsed time of $5 \mathrm{hr}$ since treatment) (Fig. 5A). The change in adhesion induced by DMF parallels, therefore, changes in fibronectin production and fibronectin receptor expression.

AKR-MCA cells were also examined for alterations in adhesion to fibronectin following treatment with DMF. Alterations in adhesion to fibronectin paralleled alterations in adhesion to plastic culture dishes in the presence of bovine serum albumin (Fig. 5B). That is, cells treated for $3 \mathrm{hr}$ with $1 \% \mathrm{DMF}$ attached and spread on fibronectin $(10 \mu \mathrm{g})$ coated dishes more rapidly than untreated AKR-MCA cells.

In additional experiments, antibodies to the human fibronectin receptor and the synthetic peptide RGDS from the cell-binding domain of fibronectin were examined for effects on AKR-MCA cell adhesion. AKR-MCA cells that had been incubated for one day with $1 \% \mathrm{DMF}$ were treated with the antifibronectin antibody or with RGDS and added to untreated or fibronectin-treated wells of a plastic culture dish. Normal rabbit serum and the synthetic peptide GRADSP served as controls. Attachment and spreading were measured in the normal way. Table 4 shows that both the antibody to the fibronectin receptor and the synthetic peptide RGDS partially inhibited AKR-MCA cell adhesion. Adhesion on untreated dishes and on fibronectin-coated dishes was inhibited equally by both reagents. The two control reagents did not inhibit adhesion (Table 4).
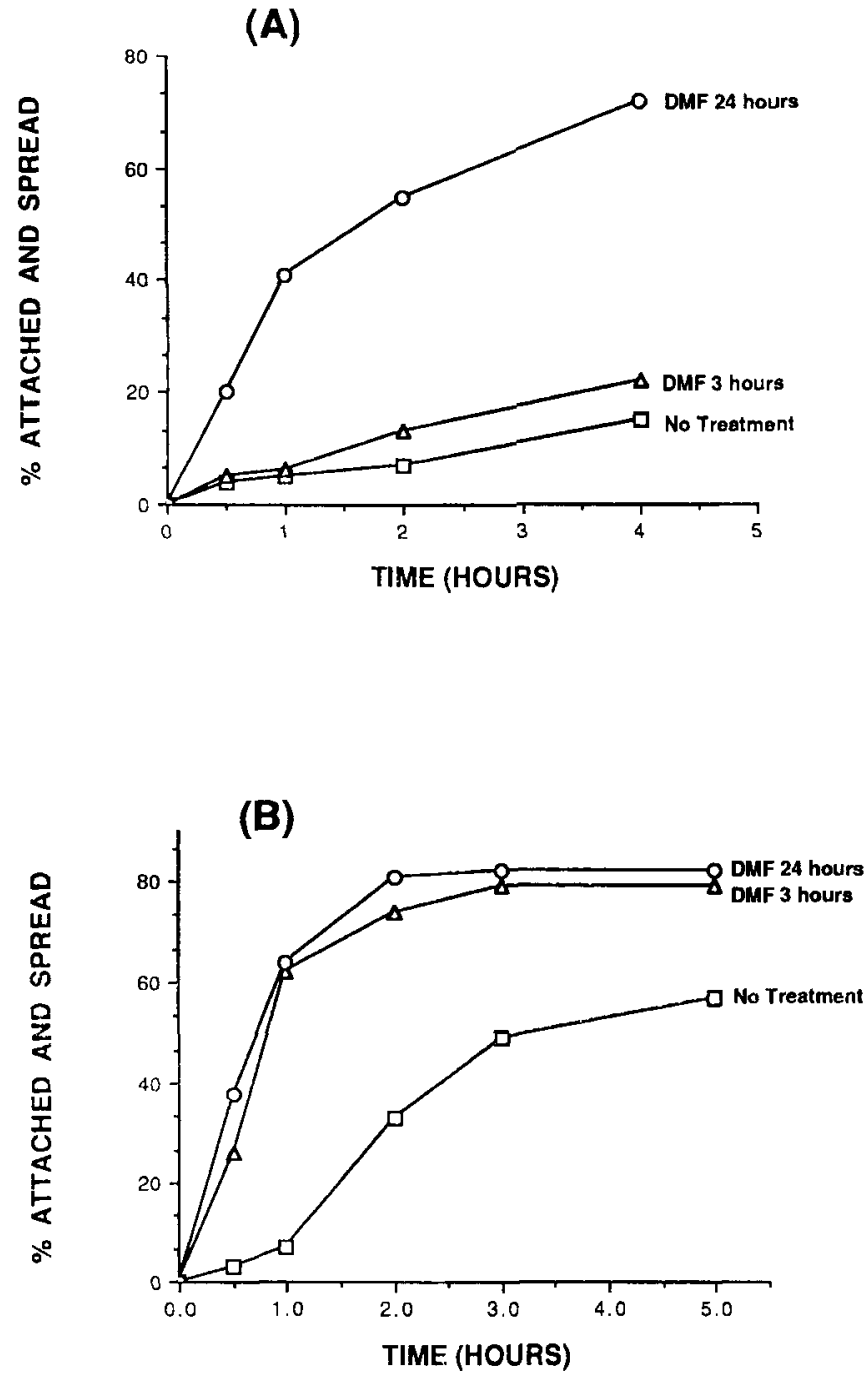

Fig. 5. Effects of DMF on AKR-MCA cell attachment and spreading on plastic culture dishes in the presence of bovine serum albumin (A) or on dishes coated with $10 \mu \mathrm{g}$ fibronectin (B). The assays were carried out as described in Materials and Methods. Values shown represent averages based on duplicate samples/data point in a single experiment. The individual values were within $10 \%$ of the mean values. The experiment was repeated three times, with similar results.

\section{DISCUSSION}

Transformation of cells is associated with a loss of surface fibronectin (Hynes, 1976; Vaheri and Mosher, 1978; Hayman et al., 1981; Alitalo et al., 1982; Chakrabarty et al., 1987, 1989b). Reacquisition of the normal phenotype following treatment with chemical differentiation agents is associated with the reexpression of surface fibronectin (Hayman et al., 1980; Milhaud et al., 1980; Charkrabarty et al., 1987, 1988, 1989a; Varani et al., 1989). What underlies the alteration in fibronectin expression during transformation and differentiation is not fully understood. Reduced fibronectin biosynthesis is at least partially responsible (Olden and Yamada, 1977; Smith et al., 1981; Taylor-Papadimitriou et al., 1981; Oliver et al., 1983; Senger et al., 1983; Tanaka and Nishida, 1985; Chakrabarty et al., 
TABLE 4. Inhibition of DMF-treated AKR-MCA cell attachment and spreading on plastic culture dishes and fibronectin-coated dishes

\begin{tabular}{lcc}
\hline & \multicolumn{2}{c}{ Percent attached and spread } \\
\cline { 2 - 3 } Treatment & Plastic/BSA & Fibronectin \\
\hline None & $\mathbf{4 4} \pm 10$ & $72 \pm 5$ \\
Antifibronectin receptor $(1: 10)$ & $12 \pm 5$ & $36 \pm 9$ \\
Normal rabbit serum $(\mathbf{1 : 1 0 )}$ & $\mathbf{4 0} \pm \mathbf{6}$ & $79 \pm \mathbf{4}$ \\
RGDS $(100 \mu \mathrm{g})$ & $16 \pm \mathbf{4}$ & $\mathbf{2 4} \pm \mathbf{5}$ \\
RGDS $(50 \mu \mathrm{g})$ & $8 \pm 5$ & $32 \pm 8$ \\
GRADSP $(100 \mu \mathrm{g})$ & $54 \pm 7$ & $81 \pm 9$ \\
GRADSP $(50 \mu \mathrm{g})$ & $50 \pm \mathbf{5}$ & $63 \pm 8$ \\
\hline
\end{tabular}

${ }^{1} \mathrm{AKR}-\mathrm{MCA}$ cells were treated with $1 \%$ DMF for 1 day and then examined for attachment and spreading on plastic culture dishes in the presence of bovine serum albumin (BSA) or dishes coated with $10 \mu \mathrm{g}$ fibronectin. Antisera or synthetic peptides were added to the assay buffer immediately before addition of cells. The percentage of cells that were attached and spread was determined after $1 \mathrm{hr}$ as described in Materials and Methods. Values shown represent averages differences between individual values and averages abased on duplicate samples in a single experiment. The experiment was repeated three times with similar results.

$1987,1989 \mathrm{~b})$. However, a reduction in fibronectin synthesis has not been observed in all transformed cells (Vaheri and Ruoslahti, 1975).

An alternative explanation to account for the reduced surface fibronectin expression in transformed cells is a reduction in capacity of the transformed cells to bind fibronectin. The fibronectin receptor has been identified on a number of different cell types as a member of the integrin family of adhesion receptors (Pytela et al., 1985; Patel and Lodish, 1986; Giancotti et al., 1986a,b; Cadarelli and Pierschbacher, 1987; Codogno et al., 1987; Confarti et al., 1989; Kerjaschki et al., 1989). Plantefaber and Hynes (1989) recently reported that the fibronectin receptor was decreased on several transformed rodent cells compared with their normal counterparts. They suggested that decreased fibronectin binding rather than decreased fibronectin production was probably the key factor underlying the reduced level of surface fibronectin expression on transformed cells. They also argued that altered fibronectin binding (rather than reduced fibronectin production) was probably critical to the alterations in adhesion that accompany transformation.

In the present study we have examined the relationship between fibronectin production and fibronectin binding in transformed AKR fibroblasts under control conditions and during induction of differentiation with DMF. DMF has been shown in previous studies to reverse the transformed phenotype in these cells (Chakrabarty et al., 1984, 1985, 1987; Levine et al., 1985). The present data indicate that both fibronectin production and fibronectin binding are greatly reduced in 3methylcholanthrene-transformed AKR cells compared with their nonmalignant counterpart (AKR-2B) cells and that both are stimulated rapidly in the transformed cells (within 5-6 hr) after treatment with DMF. We had originally hoped to utilize the time course data to determine the sequence of events that occurred following DMF treatment, i.e., to determine if changes in fibronectin production occurred prior to alterations in fibronectin binding or whether changes in binding preceeded changes in fibronectin production. These data could prove useful in efforts to understand the relationship between fibronectin production and up-regulation of its receptor. However, the similarities in the time courses for stimulation of fibronectin production and fibronectin binding do not allow us to do this. They do allow us to suggest that the two events are closely linked in the AKR cells. A similar conclusion was reached by Ignotz and Massague (1987) and by Roberts et al. (1988) in their studies on human fibroblasts treated with transforming growth factor- $\beta$ (TGF- $\beta$ ) and by Ryseck et al. (1989) in their studies on serum-stimulated fibroblasts.

The nature of the DMF-sensitive, fibronectin-binding moieties associated with the AKR cells was not delineated in the present study. When cell extracts (separated by SDS-PAGE under reducing conditions) were examined for fibronectin binding on nitrocellulose, the majority of binding occurred to moieties with apparent molecular weights of 180,150 , and $97 \mathrm{kD}$. It is possible that these moieties represent subunits of the integrin receptor for fibronectin. Alternatively, since we used extracts prepared from whole cells, it is possible that much of the binding occurred to proteins that are not present in the mature cell surface receptor. Whether these moieties are related to the mature cell surface receptor is not clear. Additional studies will be needed to determine if this is the case. If it turns out that the moieties responsible for fibronectin binding in the whole cell extract are related to the integrin receptor for fibronectin, this will be of interest in light of previous observations showing that the integrin complex from chick fibroblasts does not bind fibronectin under denaturing conditions (Buck et al., 1986).

These experiments do not definitively show that the fibronectin binding moieties present in the whole cell extracts are members of the integrin family. It is clear, however, from the studies with the antifibronectin receptor that the AKR cell extracts contain a moiety that is immunologically cross reactive with the fibronectin receptor. This moiety was detected in the extracts from the normal cells, was virtually absent in the extract from the transformed cells, and reappeared rapidly after DMF treatment of the transformed cells. The loss of this moiety after transformation and reappearance after treatment with DMF correlated with changes in fibronectin binding in the whole cell binding assay and also correlated with changes in cell-substrate adhesion under the same conditions. This is consistent, therefore, with the suggestion that the immunologically cross reactive moiety is responsible for fibronectin binding by the AKR cells and for the attendant biological activity. The finding that the same antibody, as well as RGDS, was able to inhibit the adhesion response is also supportive.

In addition to examining the relationship between fibronectin production and fibronectin binding, we also sought to delineate the relationship between both fibronectin production and binding on the one hand and cell-substrate adhesion on the other. It is clear from our data that the alterations in fibronectin production and fibronectin binding that accompany transformation and differentiation are closely associated with altered cell-substrate adhesion in the AKR cells. The transformed cells were less adherent than their untransformed counterparts to fibronectin and increased adhesion to this substrate occurred in concert with the reexpression of fibronectin binding capacity following 
DMF treatment. Interestingly, changes in adhesion to plastic culture dishes in the presence of bovine serum albumin paralleled changes in adhesion to fibronectin. This most likely reflects altered fibronectin synthesis as well as fibronectin receptor expression. Antibodies to the fibronectin receptor as well as the synthetic peptide RGDS were effective in inhibiting adhesion to the plastic culture dishes in the presence of bovine serum albumin. These data strongly support the idea that altered adhesion is a reflection of changes in both fibronectin synthesis and fibronectin binding. Based on these data and our previous data (Chakrabarty et al., $1987,1989 \mathrm{~b}$ ), we believe that the initial adhesion of rodent fibroblasts in culture (at least under serum-free conditions) is mediated through endogenously synthesized fibronectin interacting with cell surface fibronectin receptors. Since these receptors are directly linked to cytoskeletal elements (Chen et al., 1985; Damski et al., 1985), the interaction of ligand and receptor could lead to cytoskeletal reorganization and modulation of cell morphology as well as to the initial attachment of the cells to the substratum.

It should be noted that decreased fibronectin receptor expression on transformed rodent fibroblasts is not indicative of a general loss of integrins. Plantefaber and Hynes (1989) noted that several integrins capable of binding fibronectin were present on transformed rodent cells in spite of the loss of the specific fibronectin receptor. Likewise, Giancotti et al. (1986a,b) observed that Rows sarcoma virus (RSV)-transformed fibroblasts as well as control cells stained with an antibody to the integrin complex. Qualitative rather than quantitative differences in the staining patterns were seen. Furthermore, the fibronectin receptor itself is not decreased on all cells during transformation. Saga, Chen, and Yamada (1988) found increased expression of fibronectin receptors on fibrocytic tumors induced in chickens by RSV. Similar or increased levels of antifibronectin immunostaining have also been noted on the surface of transformed human cells relative to their nontransformed counterparts (Akiyama et al., 1990). Thus decreased ability to utilize fibronectin or other matrix components is not a necessary consequence of transformation.

Studies from several laboratories have shown that rodent cells express receptors for laminin (Malinoff and Wicha, 1983; Rao et al., 1983; Kramer et al., 1989; Chakrabarty et al., 1989b). These cells also synthesize laminin (Varani et al., 1983; Chakrabarty et al., 1987, $1989 \mathrm{~b})$. Thus it is possible that interaction of laminin and its receptor are involved in mediating the adhesion of rodent fibroblasts to their substratum. However, our studies with the AKR fibroblasts (Chakrabarty et al., 1987) suggest that adhesion mediated through laminin probably does not play an important role in the initial attachment of these cells to the substratum. Evidence for this includes the fact that antibodies to laminin do not interfere with attachment and spreading of the untransformed cells on bovine serum albumin-coated dishes and the fact that the transformed cells express as much (or greater amounts of) surface laminin as the untransformed cells, yet are defective in their initial attachment and spreading. Furthermore, the untransformed AKR cells produce much less laminin than fibronectin. and it accumulates much more slowlv. Thus it is unlikely that laminin plays a major role in the initial adhesion process when the cells concomitantly produce much larger amounts of fibronectin and express surface receptors for fibronectin. Although probably not involved in the initial adhesion response, laminin-laminin receptor interaction may promote adhesion at later time points. Although they are defective in their initial attachment, transformed AKR fibroblasts (Chakrabarty et al., 1987) as well as other transformed rodent fibroblasts (Varani et al., 1983, 1985; Chakrabarty et al., 1989b) that express laminin on their surface are capable of attaching and spreading on plastic culture dishes at longer time periods. In contrast, cells that are defective in both fibronectin and laminin are deficient in their initial rates of attachment and in attachment at later time points (Varani et al., 1983, 1985). Whether these in vitro observations have in vivo counterparts is not known. However, the existance of multiple mechanisms of adhesion could explain how malignant cells might demonstrate the reduced adhesiveness necessary to allow cells to separate from the primary tumor and yet have the capacity to adhere to endothelial cells or to subendothelial basement membranes at secondary sites during the process of metastasis.

\section{ACKNOWLEDGMENTS}

We acknowledge the excellent technical assistance of Yih Jan Danels. This study was supported by American Cancer Society grant IM-432 and by NIH grants CA47775 and CA38100.

\section{LITERATURE CITED}

Akiyama, S.K., Larjava, H., and Yamada, K.M. (1990) Differences in the biosynthesis and localization of the fibronectin receptor in nor mal and transformed cultured human cells. Cancer Res 50:16011607.

Alitalo, K., Keski-Oja, J., Hedman, K., and Vaheri, A. (1982) Loss of different pericellular matrix components of rat cells transformed with a T-class ts mutant of Rous sarcoma virus. Virology, 119: 347-357.

Buck, C.A., Shea, E., Duggan, K., and Horwitz, A.F. (1986) Integrin (the CSAT antigen): Functionality requires oligomeric integrity. J. Cell Biol., 103:2421-2428.

Cadarelli, P.M., and Pierschbacher, M.D. (1987) Identification of fibronectin receptors on T lymphocytes. J. Cell Biol., 105:499-506.

Carlin, B.E., Durking, M.E., Benders, B., Jaffee, R., and Chang, A.E. (1982) Synthesis of laminin and entactin by F9 cells induced with retinoic acid and dibutyrl cyclic AMP. J. Biol. Chem., 258:77297737 .

Chakrabarty, S., Brattain, M.G., Ochs, R.L., and Varani, J. (1987) Modulation of fibronectin, laminin and cellular adhesion in the transformation and differentiation of murine AKR fibroblasts. $J$. Cell. Physiol., 133:415-425.

Chakrabarty, S., Jan, Y., Brattain, M.G., Tobon, A., and Varani, J. (1989a) Diverse cellular responses elicited from human colon carcinoma cells by transforming growth factor- $\beta$. Cancer Res., 49 : 2112-2117.

Chakrabarty, S., Jan, Y., Levine, A., McClenic, B., and Varani, J (1989b) Fibronectin/laminin and their receptors in aberrant growth control in Ha-ras oncogene transformed and epidermal growth factor gene transformed FR3T3 cells. Int. J. Cancer, 44:325-331, 1989.

Chakrabarty, S., Jan, Y., Son, J., Miller, C.A and Brattain, M.G. (1985) Selective phosphorylation of cytosol proteins associated with transformation and restoration of normal phenotype in AKR mouse embryo fibroblasts. Cancer Res., 45:2170-2176.

Chakrabarty, S., McRae, L.J., Levine, A.E., and Brattain, M.G. (1984) Restoration of normal growth control and membrane antigen composition in malignant cells by $\mathrm{N}, \mathrm{N}$-dimethylformamide. Cancer Res., 44:2181-2185.

Chakrabarty, S., Tobon, A., Varani, J., and Brattain, M.G. (1988) Induction of carcinoembryonic antigen secretion and modulation of nrotein serretion/exnrescinn and fihrnnartin/laminin oynroceion in 
human colon carcinoma cells by transforming growth factor- $\beta$. Cancer Res., 48:4059-4064, 1988.

Chen, W.T., Hasegawa, T., Hasegawa, C., Weinstock, C., and Yamada, K.M. (1985) Development of cell surface linkage complexes in cultured fibroblasts. J. Cell. Biol., 100:1103-1114.

Codogno, P., Doyennette-Moyne, M., and Aubery, M. (1987) Evidence for a duel mechanism of chick embryo fibroblast adhesion to fibronectin and laminin substrate. Exp. Cell Res., 169:478-489.

Confarti, G., Zenetti, A., Colella, S., Abbadini, M., Marchisio, P.C., Pytela, R., Giancotti, F., Tarone, G., Languino, L.F., and Dejana, E. (1989) Interaction of fibronectin with cultured human endothelial cells: Characterization of the specific receptor. Blood, 73:1576$1585,1989$.

Damsky, C.M., Knudsen, K.A., Bradley, D., Buck, C.A., and Horwitz, A.F. (1985) Distribution of CSAT cell-matrix antigen on myogenic and fibroblastic cells in culture. J Cell. Biol., 100:1528-1539.

Giancotti, F.G., Comoglio, P.M., and Tarone, G. (1986a) Fibronectinplasma membrane interaction in the adhesion of hemopoietic cells J. Cell Biol., 103:429-437.

Giancotti, F.G., Comoglio, P.M., and Tarone, G. (1986b) A 135,000 molecular weight plasma membrane glycoprotein involved in fibronectin-mediated cell adhesion. Exp. Cell Res., 163:47-62.

Hayman, E.G., Engvall, E., and Ruoslahti, E. (1980) Butyrate restores fibronectin at the cell surface of transformed cells. Exp. Cell Res., 127:478-481.

Hayman, E.G., Engvall, E., and Ruoslahti, E. (1981) Concomitant loss of cell surface laminin and fibronectin from transformed rat kidney cells. J. Cell Biol., 88:352-357.

Hynes, R.O. (1976) Cell surface proteins and malignant transformation. Biochim. Biophys. Acta, 458:73-78.

Ignotz, R.A., and Massague, J. (1987) Cell adhesion protein receptors as targets of transforming growth factor- $\beta$ action. Cell, $51: 189-197$

Kerjaschki, D., Ojha, P.P., Susani, M., Horvat, R., Binder, S., Hovorka, A., Hillemanns, P., and Pytela, R. (1989) A B-integrin receptor for fibronectin in human kidney glomeruli. Am. J. Pathol., 134. 481-489.

Kleinman, H.K., Ogle, R.C., Cannon, F.B., Little, C.D., Sweeney, T.M., and Luckenbill-Edds, L. (1988) Laminin receptors for neurite outgrowth. Proc. Natl. Acad. Sci. USA, 85:1282-1286.

Kramer, R.H., McDonald, K.A., Crowley, E., Ramos, D.M., and Damsky, C.H. (1989) Melanoma cell adhesion to basement membrane mediated by integrin-related complexes. Cancer Res., 43:393-402.

Laemmli, U.K. (1970) Cleavage of structural proteins during the as sembly of the head of bacteriophage $\mathrm{T}_{4}$. Nature, 22:680-685.

Levine, A.E., McRae, L.J., and Brattain, M.G. (1985) Changes in receptor occupancy and growth factor responsiveness induced by treatment of a transformed mouse embryo cell line with $\mathrm{N}, \mathrm{N}$-dimethylformamide. Cancer Res., 45:6401-6405.

Malinoff, H.L., and Wicha, M.S. (1983) Isolation of a cell surface receptor protein for laminin from murine fibrosarcoma cells. J. Cell. Biol., 96:1475-1479.

Marks, M.E., Ziober, B.L., and Brattain, M.G. (1985) Cell surface features associated with differentiation-induction of methylcholanthrene-transformed AKR-2B fibroblasts by N,N-dimethyl-formamide. Cancer Res., 45:1276-1284

Milhaud, P., Yamada, K.M., and Gottesman, M.M. (1980) Sodium butyrate affects expression of fibronectin on CHO cells: Specific increase in antibody-mediated cytotoxicity. J. Cell. Physiol., 104. $163-170$.

Olden, K., and Yamada, K.M. (1977) Mechanism of the decrease in the major cell surface protein of chick embryo fibroblasts after transformation. Cell, 11:957-969.

Oliver, N., Newby, R.F., Furcht, L.T., and Bourgeois, S. (1983) Regulation of fibronectin biosynthesis by glucocorticoids in human fibrosarcoma cells and normal fibroblasts. Cell, 33:287-296.

Patel, V.P., and Lodish, H.F. (1986) The fibronectin receptor on mammalian erythroid precursor cells: Characterization and developmental regulation. J. Cell Biol., 102:449-456.
Plantefaber, L.C., and Hynes, R.O. (1989) Changes in integrin receptors on oncogenically transformed cells. Cell, 56:281-290.

Pytela, R., Pierschbacher, M.D., and Ruoslahti, E. (1985) Identification and isolation of a 140 kilodalton cell surface glycoprotein with properties expected of a fibronectin receptor. Cell, 40:191-198.

Rao, N.C., Barsky, S.H., Terranova, V.P., and Liotta, L.A. (1983) Isolation of a tumor cell laminin receptor. Biochem. Biophys. Res. Commun., 111:804-808.

Rieber, M., Castillo, M.A., Rieber, M.S., Irwin, J.C., and Urbina, C. (1988) Decrease in tumor cell attachment and in a $140-\mathrm{kDa}$ fibronectin receptor correlates with greater expression of multiple 34$\mathrm{kDa}$ surface proteins and cytoplasmic $54-\mathrm{kDa}$ components. Int. J. Cancer, 41:96-100.

Roberts, C.J., Birkenmeier, T.M., McQuillan, J.J., Akiyama, S.K., Yamada, S.S., Chen, W-T, Yamada, K.M., and McDonald, J.A. (1988) Transforming growth factor $\beta$ stimulates the expression of fibronectin and of both subunits of the human fibronectin receptor in cultured human lung fibroblasts. J. Biol. Chem., 263:4586-4592.

Ronnett, G.V. Knutson, V.P., Kohnski, R.A., Simpson, T.L., and Lane, M.D. (1984) Role of glycosylation in the processing of newly translated insulin proreceptor in $3 \mathrm{~T} 3-\mathrm{L}_{1}$ adipocytes. J. Biol. Chem., $259: 4566-4576$

Ruddon, R.W., Hanson, C.A., and Addison, N.J. (1979) Synthesis and processing of human chorionic gonadotropin subunits in cultured choriocarcinoma cells. Proc. Natl. Acad. Sci. USA, 76:5173-5176.

Ryseck, R.P., McDonald-Bravo, H., Zerial, M., and Bravo, R. (1989) Coordinate induction of fibronectin, fibronectin receptor, tropomyosin and actin genes in serum-stimulated fibroblasts. Exp. Cell Res., 180:537-545.

Saga, S., Chen, W.-T., and Yamada, K.M. (1988) Enhanced fibronectin receptor expression in Rous sarcoma virus-induced tumors. Cancer Res., 48:5510 -5513 .

Senger, D.R., Destree, A.T., and Hynes, R.O. (1983) Complex regulation of fibronectin synthesis by cells in culture. Am. J. Physiol., 245:144-150

Smith, H.S., Riggs, J.L., and Mosessan, M.W. (1981) Production of fibronectin by human epithelial cells in culture. Cancer Res., 39: 4138-4144.

Sporn, M.B., and Roberts, A.B. (1983) Role of retinoids in differentiation and carcinogenesis. Cancer Res., 43:3034-3040.

Tanaka, H., and Nishida, T. (1985) Butyrate stimulates fibronectin synthesis in cultured rabbit cornea. J. Cell. Physiol., 123:191-196.

Taylor-Papadimitriou, J., Burchell, J., and Hurst, J. (1981) Production of fibronectin by normal and malignant human mammary epithelial cells. Cancer Res., 41:2491-2500.

Vaheri, A., and Mosher, D.F. (1978) High molecular weight cell surface associated glycoprotein (fibronectin) lost in malignant transformation. Biochim. Biophys. Acta, 516:1-9.

Vaheri, A., and Ruoslahti, E. (1975) Fibroblast surface antigen produced but not retained by virus-transformed human cells. J. Exp. Med., 142:530-535.

Varani, J., Grimstad, I.A., Knibbs, R.N., Hovig, T, and McCoy, J.P (1985) Attachment, spreading and growth in vitro of highly malig. nant and low malignant murine fibrosarcoma cells. Clin. Exp. Metast., 3:45-59.

Varani, J., Lovett, E.J., McCoy, J.P., Shibata, S., Maddox, D.E., Goldstein, I.J., and Wicha, M.S. (1983) Differential expression of laminin-like substance by high and low metastatic tumor cells. Am. J. Pathol., 111:27-34.

Varani, J., Mitra, R.S., McClenic, B., Fligiel, S.E.G., Inman, D.R., Dixit, V.M., and Nickoloff, B.J. (1989) Modulation of fibronectin production in normal human melanocytes and malignant melanoma cells by interferon- $\gamma$ and tumor necrosis factor- $\alpha$. Am. J. Pathol., 134:827-836.

Yamada, K.M., Olden, K., and Pastan, I. (1978) Transformation sensitive cell surface protein: Isolation, characterization and role in cellular morphology and adhesion. Ann. N.Y. Acad. Sci., 312:256267. 